\title{
Gender and Gender Mainstreaming In Engineering Education in Africa
}

\author{
Kehdinga George Fomunyam, Noluthando Matola, Sibusiso Moyo
}

\begin{abstract}
In Africa, a lot of debates on the issues of gender gap and gender inequality has raised concerns in engineering education (EE) and engineering workforce. Thus, gender inequality and equity are significant in realizing Sustainable Development Goals (SDGs), and in recent years much has been done to address gender gaps, yet women are still excluded, underrepresented, segregated and relegated inengineering profession and academia. With much sensitization on gender equality, Africa is still far from addressing gender gaps in EE; hence the crux of this paper. This paper was guided by Liberal Feminism theory, focusing on women's freedom as an autonomy to be free from coercive interference, due to 'gender system' or patriarchal nature of inherited traditions and institutions. This paper takes a broad look at the concepts of gender and gender mainstreaming in EE in Africa. Specifically, it explores gender and inequality in $E E$ and how gender mainstreaming canbe enacted to address gender gaps in EE, as well as its implications in Africa. Thus, to address these gaps, recommendations such as developing gendersensitive curriculum for EE, adopting policies in facilitating women's access to training and employment opportunities as well as creating gender-sensitive career counselling were advocated.

Keywords: Africa, engineering, gender, inequality, mainstreaming
\end{abstract}

\section{INTRODUCTION}

The concept of gender mainstreaming is interpreted differently which result into an important level of misperception within various disciplines. The evolution of this concept was dated back to the clamouring for gender equality and equity from the 1980's United Nations Decade for women and from there the fourth World conference on women was held in Beijing in 1995 that pushed for gender mainstreaming globally(UN, 1995). The Beijing Platform for gender action conveyed the need for mainstreaming gender in all sub-divisions focusing on areas such as political, economic and social sphere. The vital purpose of the Beijing Platform for gender action was to sensitize and implement gender equality policies and programmes, where men and women should benefit from the programmes equally and inequality will not be continued(UN, 1995). In year 2000, the concept of gender mainstreaming was reinforced in the Economic and Social Council (ECOSOC) agreed conclusions (1997/2 \& the 23rd Special Session of the United Nations General Assembly. It got approval in the Gender and Development (GAD) dialogue,

Revised Manuscript Received on October 25, 2020.

* Correspondence Author

Kehdinga George Fomunyam*, Durban University of Technology, george@dut.ac.za

Noluthando Matola, Durban University of Technology, noluthandom@dut.ac.za

Sibusiso Moyo, Durban University of Technology, dvcrie@dut.ac.za

(C) The Authors. Published by Blue Eyes Intelligence Engineering and Sciences Publication (BEIESP). This is an open access article under the CC BY-NC-ND license (http://creativecommons.org/licenses/by-nc-nd/4.0/) as it adopts a transformatory process and practice that seeks to engage and serve as an advantage to both male and female through a systematic combination of obvious attention to sex and gender issues within workforce(UNESCO, 2018). The interests of gender mainstreaming can be incorporated in the evaluation of issues faced by a particular sex, informing policiesthat will address gender gap. Such an approach involves agenda setting characterized by monitoring and evaluation tools with the support of frameworks. Thus, this approach is often adopted in addressing gender issues as it centred on existing development agenda by making out for change amid gender inequality issues(Wang and Degol, 2015). In Africa, the inclusion of gender perspective in engineering education (EE) involves teaching of engineering as important gender initiatives, that addresses gender disparities in engineering fields. This allow engineering students to have a better insight in matters that concerns gender and how gender mainstreaming can be applied to the content of engineering subjects, with the likelihood to positively affect engineering students directly or indirectly(USAID, 2015). Hence, it is unusual for engineering students to be affected differently by technological developments by being gender sensitive. Importantly, it becomes imperative for engineering academia to avoid gender biases on the content ofEE curriculum and programmes, as EE modules do not consciously identify gender differences or possible omissions in relation to gender, sex (in biological) or social and cultural aspects (exploring gender)(UNESCO, 2018a). This may produce outputs based on gender stereotypes or masculinity patterns and such interests will tend towards oversimplification as if it was germane to the engineering profession. Mainstreaming gender is very key in engineering education as it improves the quality of instructional materials, revealing the social relevance of the resulting understanding and innovations that will enhance impact of gender equality in Africa engineering institutions(David, 2017; UNESCO, 2017a). This will facilitate an indepth understanding of gender perspective and help in consideringcentral views from engineering academia and industrial professionals. Thus, theoretical conceptualisations and empirical evaluation of gender and gender mainstreaming in EE can not be avoided. But imploring teaching with gender perspective in EE will enhance EE students to think critically in identifying social stereotypes, gender norms and roles(Jones et al., 2013; David, 2017). Hence, engineering students will learn to problematize predominant socialisation patterns and at the same time developing unique skills that will enable them to avoid gender blindness in their future career.

\section{Published By:}

Blue Eyes Intelligence Engineering

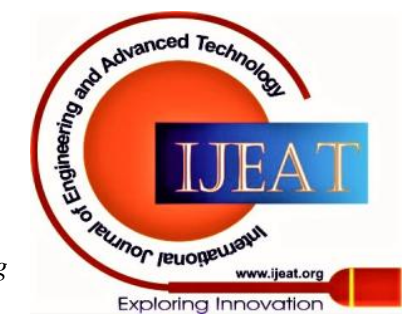




\section{Gender and Gender Mainstreaming In Engineering Education in Africa}

Teaching gender perspective inculcated in EE curriculum programmes guarantee that technological impacts are developed by engineers established on scientific proof which buttressthe relevance and quality of gender mainstreaming in EE(OECD, 2012).

The gender dimension of skills in EE requires engineering academics and students to be concerned in developing logical thinking along a shared commitment with multiplicity in modern engineering society. As this ranges from respect for fundamental rights to the equality of women and men as well as non-discrimination in engineering academia and industries. Hence, this paper presents a systematic review methodology which explore gender and gender mainstreaming in EE in Africa. The systematic review method adopted in this paper identifies and appraise published articles from year 2013 to 2020 in the fields of Engineering, Education and Sociology systematically. This was to appraise published reviews on the study objectives and to discuss its implications with recommendations. The main objective of this paper is to fill the research gap by contributing to the overall understanding of gender and gender mainstreaming excellence in EE in Africa. Specifically, we explore gender and inequality in $\mathrm{EE}$; and to examine the enactment of gender mainstreaming in EE; as well as its implications for EE in Africa, hence, recommendations were advocated.

\section{THE RESEARCH GAP}

Engineering education has an economic and social implication it has on development and growth across the globe, Africa region inclusive. Thus, the education of engineers in the 21st century is beginning to adopt gender perspective in EE, as efforts are needed to address gender gaps in engineering profession(Wang and Degol, 2015). Such efforts include addition of gender perspectives in EE curriculum programmes and learning instructional materials as well as gender skills' development in EE. This aid in raising consciousness in gender and gender mainstreaming in EE in Africa(Morley, 2010).Yet, there is a growing concern on gender gaps that has a perturbing reflection in $\mathrm{EE}$, as gender issues have still remained marginal to what is contemplated to be imperative and critical issues in EE, as debates on gender inequality cannot be secluded from wider engineering workforce milieus. Hence, there is a clear discrepancy and a wide gap in EE interrogating African traditional policies and practices that is associated with marginalization of women in EE and ascribing engineering profession as a male-dominated field(WEF, 2017). The fact remains however, that the debates on gender issues cannot be isolated from disparities in cultural interplay and religious mix-up that controls the general society; hence the crux of this paper. The critical questions are: What is the overall understanding of gender and gender mainstreaming in EE in Africa? How does gender inequality affects EE in Africa? What is the impact of gender mainstreaming enactment on EE in Africa? What can EE do to address this gender gap in order to rebuilding gender equality and equity in engineering profession? What are the implications of gender gaps in EE in Africa? The answer to these questions are critical, urgent and unavoidable by all stakeholders

within or outside engineering institutions, hence recommendations were advocated.

\section{LITERATURE REVIEW}

The rapid growing impact of engineering field isfundamental to economic growth and development, as gender gap is one of the greatest challenges of the 2030 Agenda for Sustainable Development Goal plaguing EE and industrial profession(UNESCO, 2016; 2017). Therefore, a significant increase in the number of women entering and remaining in engineering careers are needed to achieve SDG progression in modern and technological demanding society. In year 2018, the 70th anniversary of the Universal Declaration of Human Rights was celebrated, in which gender equality and access to science and engineering fields were recognized as human rights(UN, 2020). This was organized to remind individuals that gender equality in science, technology and innovation (STI) is both critical for sustainable development, but primarily a human right. Besides, sustainable development itself requires more engineering science and scientists, who will expatiate on gender perspectives in EE. The 2030 Agenda and its 17 SDGs recognize this obviously, as deliberated upon that if the world needs more scientists in engineering areas, it cannot afford losing half of its population from the scientific and engineering workforce(Aiston and Jung, 2015).

That is why gender equality is one of the two global priorities at United Nations Educational, Scientific and Cultural Organization (UNESCO). Gender equality in engineering science and education cannot be achieved without working to overcome gender gaps and disparities in access to, impact on, and benefit of STI(Alblooshi and May, 2018).There are three keypurposes for promoting gender equality in STI. First, is the rights-based, or social justice argument as year 2018 is the 70th anniversary of the Universal Declaration of Human Rights, in which gender equality and access to science and engineering are recognized as human rights(WEF, 2017). Second, sustainable development itself requires more engineering, science and scientists, as the 2030 Agenda and its 17 SDGs recognize that the world needs more scientists and cannot be exempted from the scientific and engineering workforce. Third, sustainable development also requires new and better science, including interdisciplinary science, which has been established and seen where women have contributed in their particular perspectives, approaches and priorities as the outcomes were more varied and relevant(Elu, 2018). Over the past decades, the global community has made significant efforts to inspire and engage women and girls in engineering education and other careers. Yet, despite amazing gains, women and girls continue to be excluded from participating fully in engineering programmes, and progress is uneven(AAS, 2018). While a growing number of women are enrolling in science studies at the university levels, many drop out before reaching the higher levels in their careers. UNESCO Institute for Statistics (2018) revealed that only

Published By:

Blue Eyes Intelligence Engineering and Sciences Publication (C) Copyright: All rights reserved.

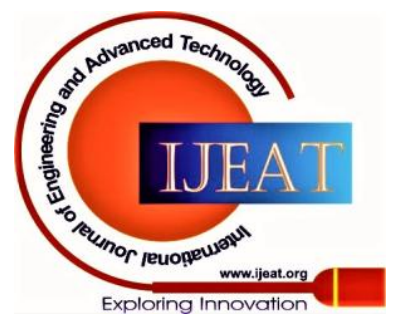


$28.8 \%$ of the world's researchers are women and only onefourth (27\%) of all countries had reached parity in 2016 (UNESCO, 2013; UNESCO, 2018). Therefore, contemporary gender imbalance in engineering field is partly a major consequences of long-term policies established at various levels, in addition to social and cultural factors. The historical background displayspath of women's increased participation in science and engineering as well as the expansion of the latter since the mid-20th century. However, evidence highlights that women have been proportionally higher in number in early higher educational levels; but women in science and engineering fields were reducing consistently and subsequently through each level of career development, as well as establishing perpendicular discrimination(Strachan et al., 2018). Besides, the 2018 global average proportion of female researchers was $28.8 \%$ and only $35 \%$ of all students enrolled in Science, Technology, Engineering and Mathematics (STEM)-related fields study were women(Alblooshi and May, 2018; AAS, 2018). Gender parity amongacademics has been reached in Central Asia with 48.1\% and Latin America with $45.4 \%$ of them were women researchers respectively; while at the national level, $30 \%$ of all countries with such available data had reached parity in 2016. Notably, other regions of the globe appear relatively far from reaching parity as only 23.4\% of researcher were women in East Asia and the Pacific, and in South and West Asia has a cumulative statistical figure of 18.5\%(UNESCO, 2013). In Africa, women scientists have a key role to play in scientific leadership in contributing to the continent's development and transformation; yet they remain significantly underrepresented in higher education and in science, technology, engineering, and mathematics (STEM)(AAS, 2018). Globally, only $53 \%$ of the world's Bachelor's and Master's degree graduates accounted for women and $43 \%$ of women were $\mathrm{PhD}$ graduates, while $28 \%$ of them were reported to be researcher in all fields of discipline. Thus, only $30 \%$ of women in higher education have moved into STEM-related field. Comparably, only $30 \%$ of researchers in all subject areas were women in sub-Saharan Africa (Aiston and Jung, 2015). For instance, in Cameroon in West Africa region, enrollment in tertiary education was estimated at $20 \%$ for men and 15\% for women in year 2017, and women only constituted $22 \%$ of Cameroonian researchers, while only $7 \%$ of academics have rose to the rank of full professor. Similarly, between year 2011 and year 2013, there was an increase in the proportion of women researchers in South Africa (43.7\%), Egypt (42.8\%), Morocco (30.2\%), Senegal (24.9\%), Nigeria (23.3\%), Rwanda (21.8\%), Cameroon (21.8\%), and Ethiopia (13.3\%) (Oanda and Akudolu, 2010; Egne, 2014; Hills, 2015; Fajardo and Erasmus, 2017; Odaga, 2020). Generally, an optimistic tendency is conspicuous in countries wheredata were available on female researchers' distribution. At the national level, 30\% of all countries with available data on the national share of female researchers had reached parity in 2016(UNESCO, 2017). However, countries that have reached gender parity in terms of researchers are still facing key challenges in accomplishing it in all facets, since perpendicular and parallel discrimination persevere as impediments to women in engineering workforce. Most recent available UIS data show that, out of 87 countries, $24 \%$ have more than $45 \%$, the lowest bound for gender parity, female researchers in the fields of natural sciences and engineering, whereas 54\% have more than $45 \%$ in social sciences and humanities(Strachan et al., 2018). In addition, women occupy only a small minority of top-level positions, despite an improvement in recent years, and only 20 women have been awarded a Nobel prize in scientific discipline to date.

Gender as a significant precepts of development were obvious in gender issues across social groups, which has attracted attention in higher learning environment, affecting quality of education in Africa(Fredua-Kwarteng Effah, 2017). Several World conventions has deliberated on gender issues pertaining to women in EE, as they pointed the negative implication of gender gaps on nations' development. Engineering learning institutions play and act as a role model and engineers of gender mainstreaming as well as practicing the considerations of the approved policy documents. Thus, EE is a threshold of future decision and policy makers that have received training and exposed to the principles aligned with gender mainstreaming. Debates on gender mainstreaming in EEwill aid a better understanding ofgender perspectives with more systematic approaches to engineering profession(Strachan et al., 2018). This pose a serious implication on quality of EE focusing on mainstreaming gender to address gender gaps and disparities. Although, change needs to happen in EE in order to build better policy-relevant indicators that will address all aspects of inequality hounding women in engineering profession(UNESCO, 2017). Importantly, policy makers and relevant engineering advisory boardhave to create new approaches to map out21st century gender-related policies in making STI relevant to gender mainstreaming. International organisations have made a lot of efforts and showed commitments in eliminating gender issues and promoting females in EE in Africa(David, 2017). This has assisted in reducing the present global statistics for gender gap in EE, which have increase the visibility, participation and women's recognition of their contribution to engineering fields, from countries around the world. This strategy will strengthen policy framework that are made to transform gender perspective that are informed from evidence drawn from data collected to monitor and evaluate gender equality progress. Engineering profession have been perceived as male-dominated career as women are not given privilege to access and work in engineering industry. Women's efforts towards EE might be affected by factors that act as impediments to their accomplishment were environment, culture, religion, and institutional policies in the society(Hills, 2015; Elu, 2018). Gender mainstreaming is applicable form that can be used to close gender gaps in all spheres of life, which involves taking into consideration the gender differences in terms of rights, responsibilities and opportunities, taking into account the different gender needs in EE(USAID, 2015; UNESCO, 2018; 2018a). Thus, gender equality is not advocated as a subject of social justice in

Published By:

Blue Eyes Intelligence Engineering

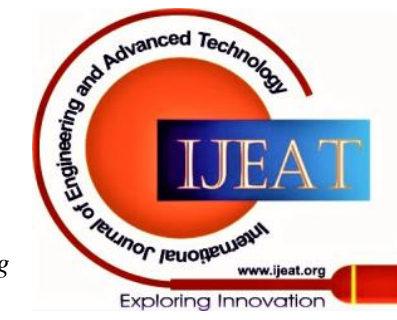




\section{Gender and Gender Mainstreaming In Engineering Education in Africa}

EEbut gender mainstreaming has rebuilt its central features that aimed at restructuring gender equality policies. This has an implication on the quality of teaching, learning and research in EE as it is applied to evaluate quality assurance in EE programmes.

\section{METHODOLOGICAL APPROACH}

Systematic literature review was conducted as recommended by Gough et al. (2017) where the author derived formulated review questions, identified relevant studies, selected studies that fit the inclusion criteria, and evaluated the quality of the research studies, as well as summarized the evidence by use of an unequivocal methodology. Based on the study research questions, relevant studies have been identified through reviewed articles archive. The descriptors "gender", "gender in EE", "gender mainstreaming in EE", and "gender mainstreaming enactment in EE" were used to locate key bases. These descriptors were also used in permutation with other descriptors such as "USA", "global", "developed countries", "developing countries" and "Africa" as these are all understatedfactors in EE (Borrego et al., 2015). Several papers(Inês Doreito et al., 2019) were identified as prospective sources of information, however,quality articles who met the following inclusion criteria were reviewed: (1) Published between 2013 and 2020; (2) enumerated gender and inequalityin EE in Africa as one of the lenses for analysis; and (3) examined gender mainstreaming enactment in EE in Africa. Again, the papers were allocated into subsections relating to study objectives and identified types of analytical themes in sampled articles were itemized. In total, there were 32 reviewed articles indicating systematic review articles. Of those 32 articles, only 25 articles clearly that were identified with the theme 'gender and gender mainstreaming in EE in Africa' were used. The other seven articles simply specified more of 'logicaltheoretical papers'. To recap the validation found in these sampled articles, appraisal of the sampled articles was completed, along with adeveloped coding sheet. These identifiedgrouping on the coding sheet involve study's objectives, research questions, methods, type of data collected, study population, and relevant findings. Also, methods used to evaluate and review published articles scientifically, were drawn from existing studies (Gough et al., 2017; Torres-Carrion et al., 2018;). This was followed by adopting logical research practices and reporting of systematic reviews were explained explicitly. After review, the principal investigator synthesized the preliminary findings and patterns recorded in summaries. The author reviewed these summaries and preliminary findings to guide the final review. After the articles were analysed, the principal investigator developed a typical sampling framework in which the articles were used to outlined the research questions. These illustrative samples were not taken verbatim, but rather synthesized to illustrate how analytical research in EE can reframe to redefine key themes and research questions in gender and gender mainstreaming in $\mathrm{EE}$, as indicated byBrown et al. (2015). In addition, identifying and appraising process of published reviews allows researchers to describe the quality of compiled existing studies, summarize and compare the conclusions of the reviews as well as discussing the implications and recommendations of the reviews (Gough et al., 2017). The principles of systematic review methodology were emphasized in the studies to explore how enactment of gender mainstreaming policies will primarily address gender gaps in EE in Africa (Torres-Carrion et al., 2018). In the discussion section, we illustrated how we outlined representative research questions presented in the reviews highlighted by the studies analysed.

\section{LIMITATIONS}

While this study focused on published articles in relation to gender and gender mainstreamingin EE in Africa, it is possible that the authors may have omitted important studies that may have included gender mainstreaming within social contexts of EEareas of research. Furthermore, it is documented that by selecting publications from 2015 to 2020, the principal investigator may have omitted earlier studies that have discuss gender and gender mainstreaming in EE in Africa. However, the focus of this work was to explore the state-of-the-art of these types of studies on gender mainstreamingin EE. Finally, we want to acknowledge that some of the studies reviewed used more than one rational theoretical framework. However, within our inclusion criteria, we focused on studies that used at least one logical context and did not analyse the impact of those that may have used a combination of these outlines.

\section{Exploring Gender and Inequality in Engineering \\ Education in Africa}

Gender is an all-encompassing idea which not only entails what men and women do in society, but to embrace cultural ideas and interpretations about their 'masculinity' and 'femininity' with structural inequalities that emanate from these differences.Thus, gender equality demands intervention that closesexisting gender gaps in EE, as differences in meaning to 'gender equality' entails different intervention frameworks and actions in engineering institutions(Egne, 2014; David, 2017). Gender equality can be viewed as equal gratification of rights and access to opportunities plus outcomes, including resources by men and women. This means that irrespective of gender, individuals are free to develop their personal abilities and make choices without set limitations such as stereotyping, placing rigid gender roles and prejudices. Thus, the core interpretation of gender equality does not mean that men and female folks are equal in all ramifications but are different with biological and physical characteristics in terms of rights, responsibilities and opportunities accessible to them both(UNESCO, 2018). The principle that male and female folks are effectively equal has been established internationally and overseen by the Commission on the Status of Women (CSW), a commission instituted by the United Nations Economic and Social Council (ECOSOC). The CSW is the main inter-governmental body concerned with promoting gender equality, and Sciences Publication (C) Copyright: All rights reserved.
Blue Eyes Intelligence Engineering

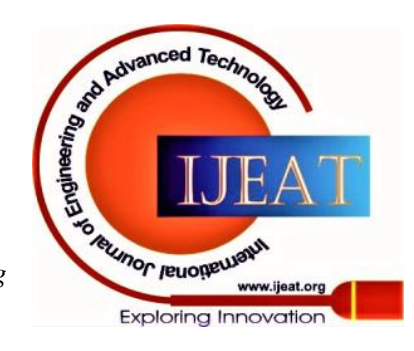


based on the Convention on the Elimination of All Forms of Discrimination against Women (CEDAW), founded in 1979 in Article 10 of the CEDAW policy documents(UN, 2020).

This policy documents lay emphasis on importance of education in promoting gender equality: "states parties shall take all appropriate measures to eliminate discrimination against women in order to ensure to them equal rights with men in the field of education." To CEDAW, gender is practiced collectively with other social constructed identities such as social class, ethnicity, race, sexuality and disability. As a result of this, a gender-sensitive education needs to be based on an intersectional approach, involving the combination of diverse types of inequality producing specific forms of discrimination(UN, 2020).

However, sexual and intellectual tensionhas dominated and complicated interactions between female and male counterpartsin EE(Strachan et al., 2018). Individual resources and personal support helped a growing number of women to complete engineering degrees in EE. Engaged female in academia and professions, with their male allies started dynamically promoting campus and cultural negotiations needed to fight discrimination against women in engineering fields and closing the gender gaps. In the process, intuitive concerns about gender nature of parenting and early education, as well as legal and cultural manifestations of second-wave radicalism, has begin to manifest itself in the acceptability of women's ambitions, and the nature of engineering itself(Aiston and Jung, 2015). From the late 1800s and throughout most of the 20th century, social revolution of gender dimensions in EE, integrates gender over former demographic factors such as race and class. Several authors have burnishes on limelight on race, while gender remains enigmatic, and the remaining effect unfortunately pushes African-American women to the relegation aspects (Bix, 2014; WEF, 2017; UN, 2020). Also, other studies considered and track important questions of how women's post-graduation, employment and professional identity in EE has made a lot of significant progress(UNESCO, 2013; Aiston and Jung, 2015; UNESCO, 2016; 2017; Alblooshi and May, 2018; Strachan et al., 2018). These studies were only conducted in the USA, Europe and elsewhere, where statistics for women's presence in engineering studies do not repeatedly correspond to USA statistical figures. Over recent decades, other countries, such as Norway, France, Portugal, and Bulgaria, have witnessed a sharp rise in women's existence in engineering fields. Although, gender discrimination was not completely eradicated in EE, but the experiences of women in non-American engineering studies have followed a particular unusual history(Bix, 2014).

Examining if Gender Mainstreaming has been Enacted in Engineering Education in Africa

Mainstreaming a gender perspective is the process of assessing the consequences for women and men of any planned action, including legislation, policies or programmes, in all areas and at all levels(Nyarko and Eshun, 2013). Also, it is an approach for making women's as well as men's concerns and experiences an integral dimension of the design, implementation, monitoring and evaluation of policies and programmes in all political, economic and societal spheres so that women and men can benefit equally and inequality is not maintained(Tsvere, 2012). The dynamic goal of mainstreaming a gender perspective is to achieve gender equality in all spheres of life. Presently, women are dramatically under-represented in science- and technology-based innovation activities, as a result of actions from barriers andbiases that were unfair to women, preventing them from full exploitation of their potentials in all ramifications(Varma, 2018). In sub-Saharan Africa (SSA), EE has an important role in addressing gender gap and since many SSA countries have implemented gender equality policies within in the university systems in the 1990s. The SSA universities in Africa has recorded some remarkable progress in female enrolment in STI and STEM programmes, however, stereotypes continue to be evident within subject areas(AAS, 2018; Alblooshi and May, 2018) Studies conducted in some SSA countries revealed that, women represent around 50\% in humanities and arts and up to $95 \%$ in nursing and social welfare, while physics, mathematics, and engineering programmes have proportions as low as below $10 \%$. Thus, the way forward to overcome these challenges is to remove negative stereotypes and promoting positive role models for women, by introducing gender perspective in school curriculum that will address gender gap(UNESCO, 2017). Conversely, there is a decline in the proportion of women taking engineering as a career path, as genderinequalities continue to persist in EE and in engineering workforce(Strachan et al., 2018). This limits the different standpoints that confirm robust engineering research output, as women's contributions and career progression are relegated. For instance, gender dimension in the university curriculum content and research practices has failed to consider the genetic differences in research assumptions that has led to inaccurate results, involving serious implications on drug effectiveness and medical protocols that were not tailored to women's needs(Frosina and Mwaura, 2016). Therefore, a gender lens is crucial for distinguishing women's input and needs for development and transformation in all spheres of life. Despite several efforts made to address gender inequalities in EE, gender gaps still exist at in EE academia and industries(Aiston and Jung, 2015). These gaps are relatively and partly connected with the consequences of social and cultural factors promoting patriarchal society.

Moreover, women have a role to play as they are essential catalysts for change, in order to act as role modeland empower other women in the same profession. Women engineers need to be more visible in research and in the media, in order to challenge stereotypes in engineering profession. Several national or regional initiatives on gender mainstreaming have started to support gender diversity and inclusion in EE(Nyarko and Eshun, 2013; Wang and Degol, 2015). But The question in mind still remains whether gender mainstreaming policies and programmes as well as its practices have been structured to counterbalance stereotypes attitudes and biases found within society and in EE? In most countries especially in Africa, and in the Fourth Industrial Revolution (4IR) era,

Published By:

Blue Eyes Intelligence Engineering and Sciences Publication

(C) Copyright: All rights reserved.

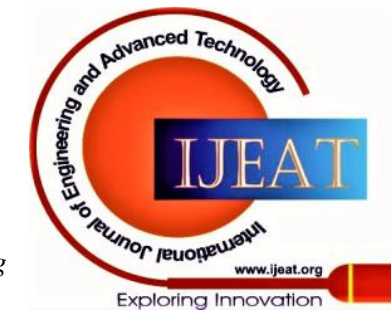




\section{Gender and Gender Mainstreaming In Engineering Education in Africa}

life sciences are feminized while engineering and experimental sciences are mostly male-dominated fields(Fredua-Kwarteng and Effah, 2017; UNESC0, 2018; 2018a).

Thus, perpendicular discrimination started emerging in engineering profession as the degree of feminisation continues to prevail in EE. Therefore, the feminization within $\mathrm{EE}$ in most countries is a well-known phenomenon, but less attention has been paid to the continued imbalance in men's favour in education management and industrial positions(Strachan et al., 2018). This imbalance has a context: women often make up the majority of civil servants, but they tend to be concentrated in positions with less authority. In OECD countries, women represent $57 \%$ of the government workforce, equating to $65 \%$ of secretarial positions, $35 \%$ of middle managers and $27 \%$ of top managers in 2010 (OECD, 2012). Thus, the attention of provide role models that can help encourage female student retention, especially important in countries with low educational attainment for girls. This is key in achieving SDGs, as education and training help in developing professional capacities in EE that will stimulate better development outcomes. However, the enactment of gender mainstreaminghas been implemented in developed and developing countries, such as African region. Hitherto, many African countries are yet to domesticate gender mainstreaming enactment in their local state and communities(WEF, 2017). This has further propelled the increase in gender disparities in Africa and in EE respectively. EE programmes should have a critical review that will design their programmes to accommodate gender perspective as this will help to curb gender gap in the profession. Also, to guarantee a successful enactment of gender mainstreaming in $\mathrm{EE}$, engineering educators are obliged to adopt gender perspective in their teaching and learning through staff development training in collaboration with gender advisory board(Wang and Degol, 2015). Such training will be structured explicitly by gender entities and view points that will address gender gaps in day to day activities with engineering students. In addition, teaching with a gender perspective in EE will help in detecting potential gender imbalance in learning environment with assessment of the diversity of engineering students. Also, there are various ways in communicating to engineering students with memorandums that will reinforce inequality between women and men, generating a "concealed curriculum" in EE(Fredua-Kwarteng and Effah, 2017). Here,the "concealed curriculum" reflects gender gaps that persist in EE, in which female academics are not promoted in their contribution to course programmes and research publications through cited studies. But most scientific expert is represented as inherently male, as gender stereotyping are strengthen in EE(Jones et al., 2013). Therefore, closing gender gaps on these grounds is not only significant in terms of granting equal opportunities to all, but a way to pool talented women that will efficiently contribute their quota to EE positively.

\section{THEORETICAL FRAMEWORK} women in education leadership positions have been called to

This paper was guided by Liberal Feminism, acquired from gender inequality theory, which waspropounded by early liberal feminists such as Mary Wollstonecraft, Judith Sargent Murray, and Frances Wright(Marilley, 1996). The theory argued that women may claim equality with men on the basis of an essential human capacity for reasoned moral agency, that gender inequality is as a result of a sexist patterning of labour division through repatterning of key institutions - law, work, family, education, and media (Bem, 1993; Lorber, 2000; 2001; Pateman, 1999; Rhode, 1997; Schaeffer, 2001). This theory can be applied to gender and gender mainstreaming in EE in Africa, as it focuses on women's ability to maintain their equality through their actions and choices.In Africa, women are accounted for minority in EE, in spite of global commitments to gender justice. United Nations (2020)has advocated gender equality as an essential part of national strategies for poverty reduction, as countries with high prevalence of female enrolment in education, are much likely to have higher level of economic output. The question of women's representation in higher education in Africa has received lot of attention, and has called for several debate in the context of broader gender equality and equity discourse in development. James Aggrey (1875-1927) stated a slogan as: "if you educate a man, you educate an individual, but if you educate a woman you educate a family, indeed a nation". This slogan suggests that the education of women is significant to the development of Africa(Varma, 2018). Thus, the first part in the liberal feminist argument is the claim for gender equality and it rest on beliefs that (1) all human beings have certain essential features-capacities for reason, moral agency, and self-actualization; (2) the exercise of these capacities can be secured through legal recognition of universal rights; (3) the inequalities between men and women assigned by sex are social constructions having no basis in "nature"; and (4) social change for equality can be produced by an organized appeal to a reasonable public and the use of the state(Pateman, 1999; Schaeffer, 2001). African women are still under-represented in EE across the continent as enrollment statistics in engineering programme is still low(Varma, 2018). Under-representation of women in EE cannot be ascribed exclusively to lack of interest, ability, or intellectual capacity, but traditional representation of engineering as a male domain discipline, and cultural practices that highlight education of men over women, as well an unsupportive STEM-related teaching environment in secondary school has contributed to the paucity of African women opting for engineering in African universities. Thus, it is clearly an issue of social injustice, which involves an inequitable distribution of engineering educational opportunities to women also(AAS, 2018; Alblooshi and May, 2018).Thus, Liberal feminists argue that society holds the false belief that women are, by nature, less intellectually and physically capable than men; thus it tends to discriminate against women in the academy, in the forum, and in the marketplace.

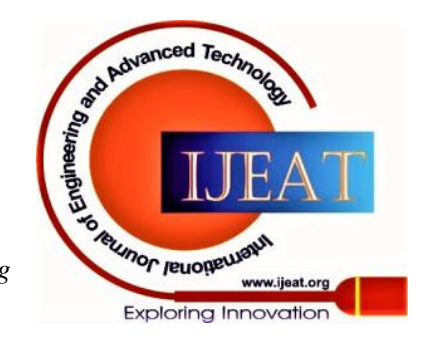


Liberal feminists believe that "female subordination is rooted in a set of customary and legal constraints that blocks women's entrance to and success in the so-called public world"; and women are made to strive for sexual equality via political and legal reform.

Conversely, analysis of gender equality is hampered by many factors(Fajardo and Erasmus, 2017; Odaga, 2020). Factors such as income and social class are frequently interwoven with gender, for the more educated the girl parents are, the less gender stereotypes that are applied to their daughters. The systematic segregation of women in the world's workforce and their restricted access to basic amenities is imposing a tremendous cost on productivity, sustainable development and economic progress worldwide(WEF, 2009). Gender disparities remain high in a variety of sectors, even in advanced nations as this diminishes an economy's capacity to grow and raise living standards.Programs and policies to reduce gender gap have the potential to significantly improve economic growth and standards of living for women and girls in Africa, with impact on poverty reduction, health and wellbeing.Girls and women are yet to experience full and equal opportunities for education and employment around the world(Strachan et al., 2018). Even though there has been progress towards gender equality in developing nations at the primary level, the secondary and tertiary educational levels remain problematic.

\section{DISCUSSION}

Globally women are often under-represented in the STEMrelated fields such as the medical field and engineering and the underrepresentation gets even worse with African women compared to the rest of the world. This has created gender gaps in engineering field as gender gaps are detrimental as they are associated with the loss of potential talent (Nyarko and Eshun, 2013; UNESCO, 2013; 2018a; Varma, 2018). A lot of international organizations within and out of Africa have made a lot of efforts in working towards closing the gaps and stereotyping of women. Thus, stereotyping threat can contribute to underrepresentation of women in engineering, as engineering is perceived as traditionally male-dominated field, which made women to be less assertive about their skills, even when performing equally with their male counterparts (Jones et al., 2013; UNESCO, 2016). A lot of young girls from high school do not express the same level of interest in engineering as boys, possible due in part to gender stereotypes. Significantly, indication of the persisting occurrence of inherent bias against female engineers were due to the acceptance that men are mathematically excellent and better suited to engineering profession (AAS, 2018). Simply, women who persist were able to overcome these problems, which enable them to find fulfilling and rewarding experiences in engineering profession. Due to this gender bias, women's choice in entering an engineering field was highly correlated to the background and exposure they had with mathematics and other science courses during high school. Most women who choose to study engineering have significant experience with regarding themselves better at these types of courses and as a result, they think they are capable of studying in a male-dominated field (David, 2017; UNESCO, 2018; Elu, 2018). Therefore, women's self-efficacy is a contributor to gender stereotype that plays a major role in the underrepresentation of women in engineering profession. Women's ability to think critically that they can be successful and perform accomplishments is associated to the choices they have when choosing a college career; and women who show high self-efficacy personalities are more disposed to choose to study in the engineering field. Selfefficacy is linked to gender roles since men often present higher self-efficacy than women, which can also be a cause to why when choosing a major course, most women opt to not choose the engineering major (UNESCO, 2017). Women are under-represented in engineering education programmes as in the workforce, as admission and graduation rates of women in post-secondary engineering programmes are very important bases of how many women go on to become engineers. Since undergraduate degrees are acknowledged as the latest point of typical entry into scientific fields, the under-representation of women in undergraduate programs contributes directly to underrepresentation in scientific fields. Besides, in the USA women who had degrees in science, technology, and engineering fields are less likely than their male counterparts to have jobs in these fields (Bix, 2014; UNESCO, 2013; 2016; 2017;). This degree disparity varies across engineering disciplines. Women tend to be more interested in the engineering disciplines that have societal and humane developments, such as agricultural and environmental engineering. They are therefore wellrepresented in environmental and biomedical engineering degree programmes, receiving $40-50 \%$ of awarded degrees in the USA (2014-2015), and women are far less likely to receive degrees in fields like mechanical, electrical, and computer engineering (Bix, 2014). Despite the fact that fewer women enrol in engineering programmes, the representation of women in STEM-based careers can potentially increase when college and university administrators work on implementing mentoring programmes and work-life policies for women. Studies shows that these rates have a hard time increasing since women are judged as less competent than men to perform supposedly male jobs(Morley, 2010; Egne, 2014; USAID, 2015; UN, 2020). Another possible reason for lower female participation in engineering fields is the occurrence of values associated with male gender role in workplace culture. For instance, women in engineering have found it difficult to re-enter workforce after a period of absence and men are less likely to take time off to raise a family; this inexplicably affects women. Issues related to class collaborations, teacher-student crescendos or the language used in the learning environment also have a role to play in gender gap. Gender blindness can obscure differences during class interactions between engineering educators and students. Notably, gender perspective allows paying attention to significant differences between academic results of male and female engineering students caused by teaching and 


\section{Gender and Gender Mainstreaming In Engineering Education in Africa}

assessment methods, which often go unnoticed in engineering academia(Strachan et al., 2018).

Gender perspective supports consideration of professional thinking and organisational philosophy of engineering disciplines itself, as there are gender differences in access to courses and curriculum revision, in which such part is played by social roles and stereotypes in EE in Africa(Jones et al., 2013; UN, 2020). It is necessary to comprehend how these mechanisms determine the choice of studies and profession, so that better actions can be taken with a better view in eliminating gender gaps. Gender-blind projects and programmes do not always take account of diverse roles and different needs attributed to male and female gender. The society often make a major mistake in maintaining the status quo that will aid in transforming the unequal structure of gender relations and learning institutions are affected by gender blindness(WEF, 2009; OECD 2012; UNESCO, 2018). Regarding the content of engineering programmes and curriculum, gender blindness has many consequences in $\mathrm{EE}$ as over-generalisation of phenomena studied on the basis of men experiences had made the situation of women invisible in EE. A false representation of such attitudes towards female folks has made women's needs seen as deviating from the ideal male model, making a blurring differences between men and women as if they were homogeneous groups. Several authors have cited and documented explanations of these differences based on gender stereotypes of the female gender (Varma, 2018).

\section{CONTRIBUTION OF NEW KNOWLEDGE}

For EE to improve, integrating internal and external drivers of gender perspective through rebuilding gender-based EE curriculum programmes is advocated for. This paper has shown inferences drawn from systematic review of sampled articles and recommendations were incorporated into the paper. The contribution of this paper to new knowledge is in general form. Firstly, it present concrete instances of gender and inequalities in EE as engineering gender gap initiatives can be sustained in domesticating engineering reforms and enactment which can be applied to EE perspectives in Africa. Secondly, the paper shows that sustaining development of gender mainstreaming enactment in EE are dependent onengineering academics and professionals as well as other relevant stakeholder, by collaborating to put more efforts in addressing gender gaps in Africa. This will aid in increasing number of enrolment of female into engineering institutions and can be achieved via working groups and advisory committees that will develop or strengthen policies and programmes to support multiple roles of women in society, including in the field of science and engineering. Open discussions will assist to set concrete goals, targets and benchmarks, as appropriate, while supporting a merit-based approach, to achieve equal participation of women and men in decision-making at all levels, especially in engineering institutions. In addition, redesigning of gender-based engineering curriculum will foster an open idea and vision in teaching and learning that is aligned with gender and gender mainstreaming curriculum revision.Thus, creating awareness of women's needs in engineering is key and should be encouraged by showcasing women's contributions in the media to sponsor engineering gender-based programmes that will expose and address gender inequalities.Though, it is tough but it can be achievable in engineering education in 21st century Africa. Hence, reflections from engineering academics on values and support of university interdisciplinary collaboration engineering research-based gender projects is imperative in curbing gender gaps in EE in Africa.

\section{IMPLICATION OF THE STUDY}

This paper presented systematic review of relevant articles to the study objectives, as cited instances and different approaches in the articles collected were reflected in the discussion. It identifies the significance and importance of gender mainstreaming in $\mathrm{EE}$ and how gender perspective can be reconstructed in EE curriculum programmes to address gender gaps. This becomes an important public issue in $\mathrm{EE}$ and provide discussions on how gender inequalities in EE can be eliminated in Africa(Oanda and Akudolu, 2010; Fajardo and Erasmus, 2017; Odaga, 2020), hence the need to engage in this research review. By focusing the study around two objectives, that reveals the strengths and benefits of the reforms of engineering curriculum and staff development will bring to students the knowledge and awareness on gender sensitive concerns that will be continually commended. Additionally, the need to sign up to the 2030 SDGs on gender will create a more inclusive, just and equitable world in the sense of sustainable development that will ensure male and female, can lead empowered and dignified lives. This is an inclusive way and gender equitable education of good quality in achieving the SDG on gender targets (UNESCO, 2018; 2018a; UN, 2020). Also, women should be allowed to have equal access to quality education and economic resources as well as equal opportunities with their male counterparts at all levels. This will bring about a significant increase in investing to close gender gap and strengthen support for institutions in relation to gender equality and empowerment of women in EE. The benefits of this approach, linking theory with practice, is that it can help educators and students to linkgender issues by inspiring and motivating students to engage in full gender-based programme participation in classroom activities. Thus, this will promote sensitization of gender disparities in EE and will give them better opportunities to have an open discussion to provide solutions on how to curb gender gaps in EE. Bearing in mind that integrating gender perspective in engineering education, especially ones initiated by individual engineering educators or departments, will be made to harmonize with the SDG approaches for the sustenance of gender mainstreaming in EE in Africa.

\section{CONCLUSION AND RECOMMENDATIONS}

This paper attempts to show that in Africa, gender mainstream is very important in improving the underrepresentation of women in engineering fields and at different career stages. 
Besides, women need to acquire and develop new set of skills and abilities to gain access to quality education. Alongside, women need to gain access to positions of decision-making power and leadership in Africa. Highlighting importance togender identity and cultural stereotypes are an overarching subject, central to the participation of women in society at large. They institute one of the most important difficulties women face worldwide, but are more generally in developing nations in Africa, as it affects women's career choices and opportunities. Gender-based initiatives in all target areas need to help women acquire new socio-cultural and gender identity in Africa. Hence, closing gender gap in engineering education is of critical importance in Africa because failure to do so means that there will be a loss of vast human resources that can contribute to national development and further embed gender inequality in society. Therefore, key recommendations are advocated as follows:

1. To achieve gender equality and equity, mainstreaming gender perspective in legislation, policies and programmes within all sectors, will address unequal access and participation of women in EE, training and skill development, including promoting women's equal access to full employment and decent work.

2. Encourage the provision of institutional and financial support for women in academic studies that can producegender-specific knowledge and incorporated into all policies and programmes on education, training andresearch, and support research, including longitudinal policy research, to identify specific gaps in EE and career pathways, in order to promote the retention of women in engineering profession.

3. Develop gender-sensitive curriculum in EE by taking concrete measures to ensure that educational materials portray women and men in positive and nonstereotypical roles, particularly in teaching of scientific and engineering subjects, in order to address root causes of segregation in EE.

\section{REFERENCES}

1. Aiston S, Jung J (2015). Women Academics and Research Productivity: An International Comparison. Gender and Education; 27 (3): 205-220.

2. Alblooshi HA, May L (2018). Engaging Women to Study STEM Through Empowerment: A Case from the United Arab Emirates (UAE). 2018 IEEE Aerospace Conference; 1.

3. Australian Academy of Science (AAS), (2018). Women in science, technology, engineering and mathematics (STEM): decadal plan.

4. Bem SL (1993). The Lenses of Gender: Transforming Debates on Sexual Inequality. New Haven: Yale University Press.

5. Bix A (2014). Girls coming to Tech: A history of American Engineering Education for Women. History Books. 4. Accessed from 10th September, 2020 from https://lib.dr.iastate.edu/history books/4.

6. Borrego M, Froyd J, Foster M (2015). What is the State of the Art of Systematic Review in Engineering Education? Journal of Engineering Education; 104 (2): 212-242.

7. Brown PR, McCord RE, Matusovich HM, Kajfez RL (2015). The use of motivation theory in engineering education research: a systematic review of literature. European Journal of Engineering Education; 40 (2): 186-205.

8. Brown TJ, Kuratko DF (2015). The impact of design and innovation on the future of education. Psychology of Aesthetics, Creativity, and the Arts; 9 (2): 147-151.

9. David ME (2017). Women and gender equality in higher education? In H. Eggins (Ed.), The changing academy - the changing academic profession in international comparative perspective: The changing role of women in higher education. Cham: Springer; 17.

10. Egne RM (2014). Gender equality in public higher education institutions of Ethiopia: the case of Science, Technology, Engineering, and Mathematics. Discourse and Communication for Sustainable Education; 5: 3-21.

11. Elu J (2018). Gender and Science Education in Sub-Saharan Africa. Journal of African Development; 20 (2):105-110.

12. Fajardo C, Erasmus M (2017). Gender disparity in South Africa: addressing the heart of the matter. 2017. Accessed from 14th September from https://www.bain.com/insights/gender-disparity-insouth-africa/

13. Fredua-Kwarteng E, Effah C (2017). Gender inequity in African university engineering programmes. International Higher Education; 89: $18-19$.

14. Frosina NL, Mwaura GM (2016). An assessment of gender mainstreaming in STI and the knowledge society in Kenya. Knowledge for better livelihoods. African Centre for Technology Studies. Pp. 1-59.

15. Gough D, Oliver S, Thomas J (2017). An introduction to systematic reviews. London: SAGE.

16. Hills J. (2015). Addressing gender quotas in South Africa: women employment and gender equality legislation. Deakin Law Rev; 20: 153-84.

17. Inês Doreito SC, Manish M (2019). The study of grit in engineering education research; a systematic literature review. European Journal of Engineering Education; Pp. 1-26. doi: 10.1080/03043797.2019.1688256.

18. Jones BD, Ruff C, Paretti MC. (2013). The impact of engineering identification and stereotypes on undergraduate women's achievement and persistence in engineering. Social Psychology of Education: An International Journal.

19. Lorber J (2000). "It's the 21st Century-Do You Know What Gender You Are?” Advances in Gender Research; 5: 119-137.

20. Lorber J (2001). Using Gender to Undo Gender: A Feminist Degendering Movement. Feminist Theory; 1: 79-95.

21. Marilley SM (1996). The feminism of equal rights. Woman suffrage and the origins of liberal feminism in the United States, 1820-1920. Cambridge, Massachusetts: Harvard University Press. Pp. 1-10.

22. Morley L (2010). Gender mainstreaming: myths and measurement in higher education in Ghana and Tanzania, Compare. A Journal of Comparative and International Education; 40 (4): 533-550.

23. Nyarko F, Eshun TB (2013). Gender mainstreaming in Tertiary Education in Ghana - The Case of University of Mines and Technology (UMaT), Tarkwa. International Journal of Modern Management Sciences; 2 (1): 44-56.

24. Oanda I, Akudolu L (2010). Addressing gender inequality in higher education through targeted institutional responses: Field experience from Kenya and Nigeria. In S. Oíhara (Ed.), Higher education in Africa: Equity, access, opportunity. New York: Institute of International Education. Pp. 69-85.

25. Odaga G (2020). Gender in Uganda's tertiary educational distribution. Social Sciences \& Humanities Open 2 (2020): 100023.

26. Organization for Economic Co-Operation and Development (OECD), (2012). Closing the Gender Gap: Act Now, OECD Publishing.

27. Pateman C (1999). "Beyond the Sexual Contract?" In Geoff Dench (ed.), Rewriting the Sexual Contract. New Brunswick, N.J.: Transaction Publishers: 1-9.

28. Rhode DL (1997). Speaking of Sex: The Denial of Gender Inequality. Cambridge, Mass: Harvard University Press.

29. Schaeffer D (2001). Feminism and Liberalism Reconsidered: The Case of Catharine MacKinnon. American Political Science Review; 95: 699-708

30. Strachan R, Peixoto A, Emembolu I, Restivo MT (2018). Women in Engineering: Addressing the Gender Gap, Exploring Trust and Our Unconscious Bias. 2018 IEEE Global Engineering Education Conference: 2088.

31. Torres-Carrion PV, Gonzalez-Gonzalez CS, Aciar S, RodriguezMorales G. (2018). Methodology for systematic literature review applied to engineering and education. 2018 IEEE Global Engineering Education Conference (EDUCON), Tenerife. Pp. 1364-1373.

32. Tsvere M (2012). Gender mainstreaming in higher education: Experiences from Africa. Zimbabwe International Journal of Open and Distance Learning. International Research Conference-Special Edition 2012. Pp. 87-93.

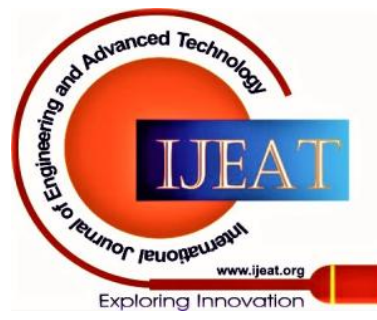




\section{Gender and Gender Mainstreaming In Engineering Education in Africa}

33. United Nations (1995). Beijing Platform on Education and Training of Women, 1995. Accessed on 9th September, 2020 from https://www.un.org/womenwatch/daw/beijing/platform/educa .htm.

34. United Nations Educational, Scientific and Cultural Organization (UNESCO), (2017a). Measuring Gender Equality in Science and Engineering: the SAGA Toolkit. SAGA Working Paper 2. Paris, UNESCO.

35. United Nations Educational, Scientific and Cultural Organization (UNESCO), (2018a). SAGA Survey of Gender Equality in STI Policies and Instruments. SAGA Working Paper 3. Paris, UNESCO.

36. United Nations Educational, Scientific and Cultural Organization (UNESCO), (2018). Telling SAGA: Improving Measurement and Policies for Gender Equality in Science, Technology and Innovation. SAGA Working Paper 5, Paris, 2018.

37. United Nations Organization for Education, Science and Culture (UNESCO), (2017). UNESCO Institute for Statistics. Women in science factsheet. 2017. Accessed on 16th September, 2020 from http://www.uis.unesco.org/ sites/default/files/documents/fs43-womenin-science-2017-en.pdf.

38. United Nations Organization for Education, Science and Culture (UNESCO), (2016). Education and literacy. Institute for Statistics. Cameroon. Accessed on 13th September from Error! Hyperlink reference not valid..org/en/country/cm.

39. United Nations Organization for Education, Science and Culture (UNESCO), (2013). Percentage of female researchers within the total number of researchers by country. Paris: United Nations Organization for Education, Science and Culture.

40. United Nations, Convention on the Elimination of all Forms of Discrimination against Women (CEDAW). Accessed from 10th September, 2020 from https://www.un.org/womenwatch/ daw/ cedaw/text/convention .htm

41. United States Agency for International Development (USAID), (2015). Gender Equality in Science, Technology, Engineering, Agricultural Sciences and Mathematics (STEAM) Academic Pipeline: Challenges Transferring Knowledge to Practice. United States Agency for International Development. Pp. 1-38.

42. Varma R (2018). U.S. Science and Engineering Workforce: Underrepresentation of Women and Minorities. American Behavioral Scientist; 62 (5): 692-697.

43. Wang MT, Degol JL (2015). Gender Gap in Science, Technology, Engineering and Mathematics (STEM): Current Knowledge, Implications for Practice, Policy and Future Directions. Accessed on 15th September, 2020 from https://www.ncbi.nlm.nih.gov/pmc/ articles/PMC5404748/.

44. World Economic Forum (WEF), (2009). The global gender gap report 2009.

45. World Economic Forum (WEF), (2017). Insight Report: The global gender gap report. 2017. Accessed from 12th September from http://www.weforum.org/docs/WEF_GGGR 2017.pdf.

\section{AUTHOR PROFILE}

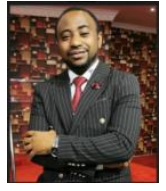

Dr. Kehdinga George Fomunyam, Institute for Systems Science, Durban University of Technology, Durban, South Africa.

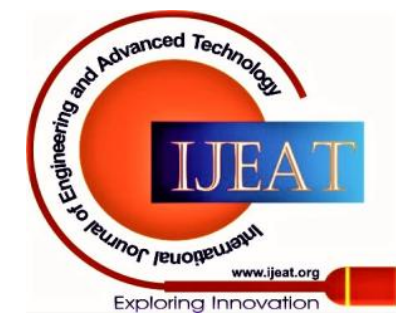

